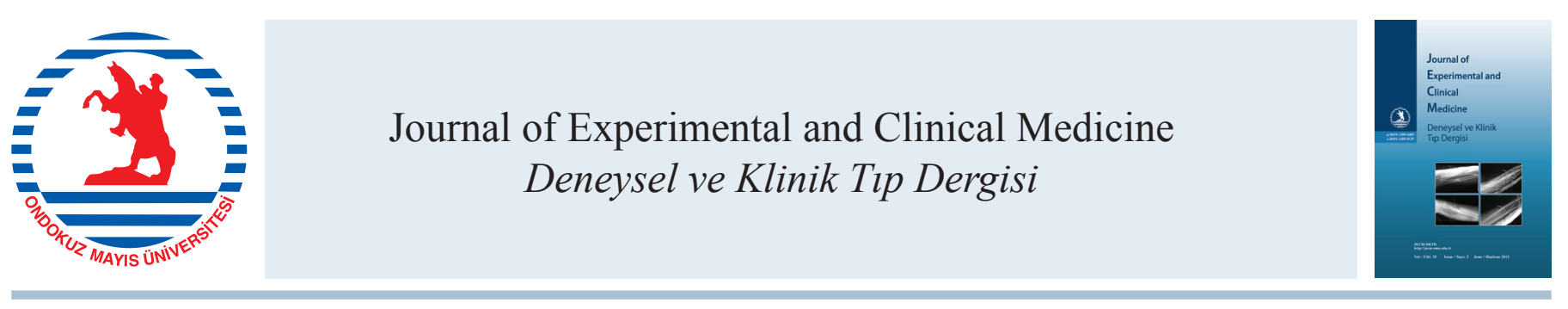

Derleme / Review

doi: $10.5835 /$ jecm.omu.29.02.002

\title{
Gebelikte parasetamol kullanımı
}

\section{Paracetamol use in pregnancy}

Evren Şavlı

Harran Üniversitesi Tıp Fakültesi, Tıbbi Farmakoloji Anabilim Dalı, Şanlıurfa, Türkiye

\begin{tabular}{|c|c|}
\hline \multicolumn{2}{|c|}{ MAKALE BİLGÍLERİ } \\
\hline \multicolumn{2}{|c|}{ Makale geçmişi } \\
\hline Geliş tarihi & $: 01 / 08 / 2011$ \\
\hline Kabul tarihi & : 02 / 08 / 2011 \\
\hline
\end{tabular}

\section{Yazışma Adresi:}

Evren Şavlı

Harran Üniversitesi,

Tıp Fakültesi,

Tıbbi Farmakoloji Anabilim Dalı,

Yenişehir Kampüsü,

Şanlıurfa, Türkiye

e-posta: evsavli@yahoo.com

\section{Anahtar Kelimeler:}

Gebelik

Parasetamol

Güvenlik

Yan etkiler

Risk

\section{Key words:}

Pregnancy

Paracetamol

Safety

Side effects

Risk

\section{ÖZET}

Gebelikte parasetamol kullanımı yaygın kabul görmekte ve gebelikte analjezik ve ateş düşürücü tedavide oldukça sık kullanılmaktadır. Yıllardır yaygın kullanımına rağmen, gebelikteki kullanımının güvenliği pek çok araştırma ile değerlendirilmeye devam edilmektedir. $\mathrm{Bu}$ derlemede gebelikte parasetamol kullanımının sonuçları hakkında literatürdeki yeni deneysel ve klinik çalışmaların sonuçlarına dikkat çekilmek istenmektedir. Klinisyenler, gebelikte parasetamol kullanımının fetus gelişimi üzerinde olası istenmeyen etkilerinin farkında olmalıdırlar. Parasetamole alternatif olabilecek ilaçların da kendilerine has risk profilleri olduğu hatırlandığında, günümüzde gebelerde analjezik ve ateş düşürücü etkilerinden dolayı hala değerli ve en çok tercih edilen ilaç olmaya devam etmektedir.

J. Exp. Clin. Med., 2012; 29:91-94

\begin{abstract}
Paracetamol use in pregnancy is commonly recommended and is frequently used as an analgesic and antipyretic treatment. Although it has been in common use for decades, questions about its safety in pregnancy are still being evaluated in many research studies. The objective of this paper is to take attention to the results of new experimental and clinical studies on pregnancy outcome after paracetamol use in the literature. Collectively, the results points to a scenario that the use of paracetamol in pregnancy may have possible unwanted effects on the development of fetus that clinicians should be aware of. As a result, use of paracetamol as an analgesic and antipyretic drug during pregnancy appears to be still most-preferred and valuable choice when considering the risk profiles of its alternatives.

J. Exp. Clin. Med., 2012; 29:91-94
\end{abstract}

Gebelerde en sık rastlanılan şikayetlerden birisi ağrıdır. Hamilelik sırasında çeşitli endikasyonlarda ağrı kesici ilaçların kullanılması gerekebilir. Ağrı kesici ilaçlar "basit" ilaçlar değildir ve içerdikleri etken maddeler anne ve fetus organları üzerinde çeşitli olumsuz etkiler oluşturabilir. Parasetamol 1950'lerin ortasında piyasaya çıkışından beri ağrı kesici ve ateş düşürücü etkilerinden dolayı tüm yaş grubundaki hastalarda kullanılmaktadır (Dharmage ve Allen, 2011; ACPA, 2011). Yayınlarda ve yaygın kabul gören tedavi kılavuzlarında gebeliğin her döneminde, kısa süreli olarak, terapötik dozlarda ağrı ve ateşte ilk tercih olarak parasetamole yer verilmektedir(WHO, 2003; Robson, 2011). Amerikan Gida ve İlaç Dairesi (FDA) ilaçları teratojenik etki potansiyellerine göre 5 kategori içinde A'dan X'e doğru sınıflandırmıştır. Ülkemizde Sağlık Bakanlığı da ilaç prospektüslerine ilacın içinde bulunduğu gebelik kategorisinin uyarılar bölümünde yazılmasını şart koşmaktadır. Hamilelerde ilaç seçimi ve uygulamasında mümkün olduğunca, FDA sinıflamasına göre A ve B grubunda bulunan ilaçlar seçilmeli ve çoklu ilaç kullanımından kaçınılmalıdır. 
A kategorisi: Bu konuda yapılan kontrollü araştırmalar ilacın ilk trimesterde fetus üzerinde zararının olduğunu göstermemiştir. Daha sonraki dönemlerde de ilacın zararlı olduğu yönünde kanıt yoktur. Bu kategori içerisindeki ilaçlar gebede en güvenilir ilaçlardır.

B kategorisi: $\mathrm{Bu}$ kategorideki ilaçlar aşağıdaki durumlardan birine uyarlar.

1-İlaçlar hayvanlarda teratojenik etkiler göstermemiştir ancak hamilelerde klinik deneyim yetersizdir.

2-Deney hayvanlarında yapılan çalışmalar ilacın fetotoksik etkisini göstermiştir, ancak hamilelerde yapılan kontrollü klinik çalışmalar fetotoksik etkiyi doğrulamamıştır (Süzer, 2008). B kategorisi içindeki ilaçlar gerekliyse hamilelikte kullanılabilirler. Parasetamol, gebelik kategorisi olarak B grubu içindedir.

C kategorisi: Aşağıdaki durumlardan birine uyarlar.

1-İlaçların hayvanda embriyosit ve teratojenik etkileri gösterilmiştir, ancak hamilelerde klinik deneyim yetersizdir.

2-Deney hayvanlarında veya hamilelerde ilaç incelenmemiştir. Bu kategori içindeki ilaçlar, doktor ilacın hamile kadına sağlayacağı yararın, fetus üzerinde potansiyel zararından daha fazla olacağına inanıyorsa kullanılmalıdır.

D kategorisi: İlacın insanda fetus üzerine zararlı etkisi kanıtlanmıştır. Bu kategori içindeki ilaç, ilacın kullanılmaması durumunda anne adayı ve fetus daha büyük risklerle karşılaşacaksa, yarar-zarar oranı dikkate alınarak, yaratabileceği olası riskler anne adayına detayları ile anlatılarak kullanılmalıdır.

X kategorisi: $\mathrm{Bu}$ kategori içindeki ilaçların deney hayvanları ve hamilelerdeki incelemeleri ilacın fetusa zararını göstermiştir. Aynı zamanda, bu kategorideki ilaçların hamilelerde kullanılmalarının yararları, fetusa zararlarının yanında önemsiz kalır. X kategorisi içindeki ilaçlar, hamilelerde ve hamile kalma olasılığ kontrendikedir ve hiçbir şekilde kullanılmamalıdır (Süzer, 2008).

Amerika'da (ABD) en yaygın kullanılan 'tezgâh-üstü' (reçetesiz) ilaç parasetamoldür ve bu nedenle gebelikte, en sık aşırı dozda kullanım vakaları parasetamol ile görülür. Plasentayı geçerek aşırı dozlarda fetal ve maternal hepatotoksisiteye neden olur (Wilkes ve ark., 2005). Hepatotoksisitesinden, karaciğerde metabolizma sonucu oluşan bir oksidasyon ürünü olan N-asetil-p-benzokinonimin sorumludur (Kayaalp, 2009). Gebelikte aşırı dozda parasetamol ile zehirlenme vakalarında plesantayı geçebilen, hem annede hem de fetüste oluşan toksik metabolitlere yapışarak, toksisiteyi azaltan $\mathrm{N}$-asetilsistein tüm gebelik dönemlerinde kullanılabilir (Wilkes ve ark., 2005).

Onüç Ocak 2011'de FDA, parasetamole bağlı zehirlenmelerin ve karaciğer toksisitelerinin önüne geçebilmek amaciyla, ABD'de parasetamol içeren ilaçlarda dozu 325 mg'a indirmiştir. FDA ayrıca günlük maksimum dozun 4000 mg'1 geçmemesini önerirken, parasetamol içeren ilaçlara, karaciğer hasarı için karakutu uyarısı konulmasına karar vermiştir.

Gebeliğin herhangi bir trimesterinde standard dozlarda parasetamol kullanımı ile fetal yan etkiler görülmediğine dair günümüze kadar biriken literatür bilgilerimize karşın, son y1llarda gebelikte parasetamol kullanımı ile ilgili yayımlanan bazı çalışmalar dikkatlerin parasetamol üzerine çekilmesine neden olmuştur (Robson, 2011). Gebelikte parasetamole maruziyetin araştırıldığı hayvan çalışmalarında, konjenital malformasyonu artırdığına ilişkin veriler saptanmamış sadece önerilen maksimum insan dozunun 2 katı kullanılmış bazı çalışmalarda, fetotoksisiteye neden olduğu gösterilmiştir. Bununla beraber literatürde gastroşizis gelişmesi, amniyotik band defekti, nöral tüp defekti veya konjenital kalp hastalığ riskini artırdığına dair ortaya konmuş istatistiksel açıdan anlamlı veriler yoktur (Scialli ve ark., 2010). Prenatal parasetamole maruziyet ile ilgili insan çalışmalarında düşük yapma, düşük doğum ağırlığı, gestasyonel yaşa göre küçük doğma veya preterm doğum komplikasyonları (bronkopulmoner displazi, intrakranyal kanama, prematür retinopatisi ve anemisi gibi) ile bir bağlantısı gösterilememiştir (Rebordosa ve ark., 2008; Scialli ve ark., 2010). Aspirin, parasetamol gibi ağrı kesicilerin sürekli kullanımları durumunda hipertansiyon riskinin arttığına dair görüşler olmasına karşın hali hazırda, gebelerde parasetamol kullanımı ile hipertansiyon gelişimi riski arasında anlamlı bir ilişki ortaya konamamıştır. Fakat Rebordosa ve ark.larının yayınında, gebelikte parasetamol kullanımı ile prostasiklinlerin azalışına bağlı gelişen preeklampsi ve preterm eylem arasında bir bağlantı olabileceği ifade edilmektedir (Rebordosa ve ark., 2010). Buna karşın literatürde, parasetamol kullanmayan annelerde preterm eylem görülme oranı, kullananlardan daha yüksek bulunmuş, parasetamol kullanımı ile arasındaki olası bağlantı doğrulanamamış (Czeizel ve ark., 2005), preterm doğum komplikasyonlarını artırdığına dair istatistiksel bir bağlantı gösterilememiştir (Scialli ve ark., 2010).

Momma ve Takeuchi'nin, (1983) 24 ayrı nonsteroid antiinflamatuvar ilacın (NSAIII) son dönem gebe Wistar ratlarda, fetüs duktus arteriozusu üzerine etkilerini değerlendirdikleri çalışmalarında, 21. gün gavaj ile uygulanan parasetamolden 4 saat sonra çıkarılan fetüs duktus arteriozuslarında, $10 \mathrm{mg} / \mathrm{kg}$ parasetamol uygulanmış rat duktus arteriozus/pulmoner arter oranının \% 25 azaldığı, $1000 \mathrm{mg} / \mathrm{kg}$ uygulananlarda ise \% 80 azalma olduğu tespit edilmiştir. Fakat bu çalışma hayvan sayılarının yetersizliği ve aslında parasetamolün rat duktus arteriozusuna 'zayıf etki gösterdiği’ (önerilen insan dozunun üzerinde dozlarda, fetal rat duktusunda daralma yapması) şeklinde eleştiriler almıştır (Scialli ve ark., 2010). Günümüz literatüründe parasetamolün duktus arteriozus üzerinde daraltıcı yönde etkilediğini istatistiksel açıdan anlamlı olarak gösterecek daha çok sayıda çalışmaya ihtiyaç vardır. Son dönemin yaygın tartışma konularından biri de gebelikte parasetamol kullanımı ile, bu annelerden doğan bebeklerde lösemi gelişme riski arasında bir bağlantının olup olmadığıdır. Bu klinik durumla ilgili istatistiksel olarak anlamlı bir bağlantı gösterilememiştir (Ognjanovic ve ark., 2011).

Literatür incelendiğinde gebelikte parasetamol kullanımının fetal ürogenital sistem üzerine etkilerini araştıran yayınların sayısının hızla arttığı görülmektedir. Kristensen ve ark.' nın 2011 yılında 1040 Danimarkalı ve 1470 Finlandiyalı erkek bebeği değerlendirdikleri çalışmalarında, gebelikte annelerin parasetamol, asetil salisilik asid ve ibuprofen gibi NSAİ ilaçları kullanımı ile bu annelerin erkek bebeklerinde kriptorşitizm görülme riski arasındaki bağlantı araştırılmış, gebeliğin herhangi bir döneminde parasetamol kullanımı ile arasında, istatistiksel açıdan anlamlı bir ilişki gösterilememiştir, ancak eşzamanlı farklı ağrı kesicilerin kullanımı ile riskin arttığı ifade edilmiştir. Aynı çalışmada 
prenatal olarak (gebeliğin 13-21. günleri süresince ve 21. gün sezeryan ile çıkarılan) parasetamole $(150,250$ ve $350 \mathrm{mg} / \mathrm{kg} /$ gün) maruz bırakılmış Wistar ratlarda anogenital mesafede (AGM) parasetamolün her 3 dozu ile azalma tespit edilmiş, sadece $350 \mathrm{mg} / \mathrm{kg} /$ gün dozu ile deney tekrarlandığında da yine aynı sonuç ortaya konmuştur. Çalışmanın diğer bir parçası olan testosteron üretiminin değerlendilmesinde ise, intrauterin parasetamole maruziyet ile üretimde bir azalma gösterilememiştir. Azalan AGM azalmış intrauterin androjen seviyesinin iyi bir göstergesi olduğundan, çıkarılan fetal testis hücrelerinden (14,5 günde) hücre kültürü oluşturulmuş ve parasetamol uygulanmıștır, prostaglandin D2 ve testosteron üretimini azalttığ 1 tespit edilmiştir (Kristensen ve ark., 2011). Jensen ve ark. (2010) ise, 47400 gebe kadının katılımı ile yaptıkları çalışmalarında, 8. ile 14. gebelik haftaları arasında parasetamol kullanımı ile bu annelerin erkek bebeklerinde kriptorşitizm görülme riski arasında anlamlı bir bağlantı olduğunu savunmaktadırlar ve ortaya koyduğu veriler ile daha çok sayıda araştırıcıyı bu konu üzerinde çalışmaya davet etmektedir. Gebelikte parasetamol kullanımının fetal ürogenital sistemi üzerindeki etkilerinin, daha güçlü saptanmasına katkısı olacak preklinik ve klinik çalışmalara ihtiyaç vardır.

Gebelik döneminde parasetamol kullanımı ile adölesan dönemde psikotik semptomların görülme riski arasındaki bağlantının değerlendirildiği bir çalışmada, parasetamol ile istatistiksel açıdan anlamlı bir bağlantısı olduğu gösterilememiştir (Gunawardana ve ark., 2011). Literatürde gebelikte parasetamol kullanımı ile astım arasındaki olası bağlantıyı araştıran çalışmaların sayısı dikkat çekici bir şekilde artmaktadır. Düzenli parasetamol kullanımında, doz bağımlı olarak, genel populasyonda alerji, astım riskinde artış, mevcut diğer solunum sistemi hastalıklarında ve akciğer fonksiyonlarında kötüleşme yapabileceğine dair yayınlar vardır (Almers ve ark., 2009; Dharmage ve Allen, 2011; Garcia-Marcos ve ark., 2011). İntrauterin parasetamol maruziyetin ileride çocukluk döneminde veya adölesan dönemde astım görülmesi riskini arttırdığı iddia edilmektedir (Eyers ve ark., 2011). Literatürde bu konu üzerine yapılmış çalışmalara getirilen bazı eleştiriler de bulunmaktadır; çocuklarda astımın belirtisi olarak, zayıf bir astım göstergesi olarak kabul edilen wheezing varlığı kabul edilirken, bazı çalışmalarda ise parasetamolün analjezik ve antipiretik olarak farklı endikasyonlarda kullanımları kabul edilmiştir. $\mathrm{Bu}$ çalışmalarda değerlendirilen parasetamol kullanımı, annede altta yatan infeksiyöz veya inflamatuvar bir hastalığın varlığına işaret etmektedir, bu mevcut kullanım endikasyonları sonuçların etkilenmiş olma olasılığını düşündürmektedir. Anneler ile ilgili değerlendirmeler içinse, annenin sigara kullanıp kullanmadığının, anksiyete skorlarının, antibiyotik kullanımlarının ve alkol alımları gibi faktörlerin göz önünde tutulması gerekliliği eleştirisi getirilmektedir (Scialli ve ark., 2010; Garcia-Marcos ve ark., 2011). Shaheen ve ark.'nın (2002) gebelik geç döneminde parasetamol kullanan (bazen, sıklıkla/hergün) ve kullanmayan annelerin çocuklarının astım gelişme riski yönünden değerlendirildiği çalışmalarında, geç gebelik döneminde parasetamol kullanımı ile bu annelerin çocuklarında astım görülmesi riski arasında pozitif bir bağlantının olduğu savunulmaktadır. Literatürde bu görüşü eleştirici ve destekleyici yayınlar da bulunmaktadır (Scialli ve ark., 2010; Dharmage ve Allen, 2011).Bu durumun patofizyolojisi hala tam olarak aydınlatılamamış olmasına rağmen, bazı aşırı doz parasetamol araştırmaları bu konu ile ilgili bu mekanizmayı açıklamaya çalışmaktadır. Parasetamol metabolizmasının fetusun gelişmekteolan solunumepitelindeki glutatyon yolaklarının inhibisyonunu indükleyerek, solunum yollarının antioksidan defans mekanizmalarını bozabileceği, bu durumun da fetal solunum sisteminde oksidatif hasara ve inflamasyona neden olabileceği öne sürülmektedir (Scialli ve ark., 2010; Dharmage ve Allen, 2011; Eyers ve ark., 2011). Son dönem yayınlarda, anne ve çocuğun GlutatyonS-Transferaz P1 polimorfizmlerinin prenatal parasetamole maruziyet ve çocukluk çağı astımı arasındaki olası bağlantıyı modifiye ediyor olabileceğinden bahsedilmektedir (Laine ve ark., 2009; Dharmage ve Allen, 2011; Eyers ve ark., 2011). Aşırı doz parasetamol araştırma sonuçlarına ek olarak, insan terapötik dozlarına eşit dozlarda parasetamolün rodentlerde rodent tip 2 pnomositlerde ve alveolar makrofajlarında hasara neden olduğu gösterilmiştir. Fakat bu terapötik dozların fetüs hava yolu hücrelerinde veya geç yaşamda nasıl hasar verdiği konusu çalışılmamıştır (Scialli ve ark., 2010; Eyers ve ark., 2011). Literatürde gebelikte parasetamol kullanımı ve çocuklarda astım gelişme riski arasındaki olası bağlantı ile ilgili olarak yapılan çalışmaların sayısı her geçen gün artmakta, bu durum araştırıcıların dikkatlerini bu konuya çekmekte ve bu konu hakkındaki bilgilerimizi artırmaktadır.

Parasetamolün fetüs üzerinde istenmeyen olası etkileri konusunda toplumsal bilgilendirme yapılarak, reçetesiz parasetamol kullanımının önüne geçilmeye çalışılmalıdır. Parasetamolün, gebelerde bilincinde olduğumuz çelişkili yönleri ileilgili, daha çok sayıda deneysel vekinik araştırmalara ihtiyaç vardır. Farmakoloji alanında hızla artan bilgilerin ve yeni klinik deneyimlerin ışığında bir ilacın kategorisinin her zaman değişebileceği göz önünde tutulmalıdır. Parasetamole alternatif olabilecek ilaçların da kendilerine has risk profilleri olduğu unutulmamalıdır. Sonuç olarak bu araştırma alanlarındaki çelişkilerine rağmen parasetamol günümüzde, gebelerde analjezik ve ateş düşürücü etkilerinden dolayı değerli bir ilaç olmaya devam etmektedir.

\section{KAYNAKLAR}

Allmers, H., Skudlik, C., John, S.M., 2009. Acetaminophen use: A risk for asthma? Curr. Allergy Asthma Rep. 9, 164-167.

American Chronic Pain Association, ACPA Consumer guide to pain medication and treatments. 2011. Edition. 17-23.

Czeizel, A.E., Dudas, I., Puho, E., 2005. Short-term paracetamol therapy during pregnancy and a lower rate of preterm birth. Paediatr. Perinat. Ep. 19, 106-111.

Dharmage, S.C, Allen, K.J., 2011. Does regular paracetamol ingestion increase the risk of developing asthma? Clin. Exp. Allergy. 41, 459-460.

Eyers, S., Weatherall, M., Jefferies, S., Beasley, R., 2011. Paracetamol in pregnancy and the risk of wheezing in offspring: A systematic review and meta-analysis. Clin. Exp. Allergy. 41, 482-489.

Garcia-Marcos, L., Sanchez-Solis, M., Perez-Fernandez, V., 2011. Early exposure to acetaminophen and allergic disorders. Curr. Opin. Allergy Clin. Immunol. 11, 162-173.

Gunawardana, L., Zammit, S., Lewis, G, Gunnell, D., Hollis, C., Wolke, D., Harrison, G., 2011. Examining the association between maternal 
analgesic use during pregnancy and risk of psychotic symptoms during adolescence. Schizophr. Res. 126, 220-225.

Jensen, M.S., Rebordosa, C., Thulstrup, A.M., Toft, G., Sørensen, H.T., Bonde, J.P., Henriksen, T.B., Olsen, J., 2010. Maternal use of acetaminophen, ibuprofen, and acetylsalicylic acid during pregnancy and risk of cryptorchidism. Epidemiology. 21, 779-785.

Kayaalp, O., 2009. Rasyonel tedavi yönünden tıbbi farmakoloji. 12.bask1. 850.

Kristensen, D.M., Hass, U., Lesné, L., Lottrup, G., Jacobsen, P.R., Desdoits-Lethimonier, C., Boberg, J., Petersen, J.H., Toppari, J., Jensen, T.K., Brunak, S., Skakkebaek, N.E. Nellemann, C., Main, K.M., Jégou, B., Leffers, H., 2011. Intrauterine exposure to mild analgesics is a risk factor for development of male reproductive disorders in human and rat. Hum. Reprod. 26, 235-244.

Laine, J.E., Auriola, S., Pasanen, M., Juvonen, R.O., 2009. Acetaminophen bioactivation by human cytochrome P450 enzymes and animal microsomes. Xenobiotica. 39, 11-21.

Momma, K., Takeuchi, H., 1983. Constriction of fetal ductus arteriosus by non-steroidal antiinflammatory drugs. Prostaglandins. 26, 631-643.

Ognjanovic, S., Blair, C., Spector, L.G., Robison, L.L., Roesler, M., Ross, J.A., 2011. Analgesic use during pregnancy and risk of infant leukaemia: A Children's Oncology Group study. Brit. J. Cancer. 104, 532-536.

Rebordosa, C., Kogevinas, M., Horvath-Puho, E., Norgard, B., Morales, M., Czeizel, A.E., Vilstrup, H., Sorensen, H.T., Olsen, J., 2008. Acetaminophen use during pregnancy: effects on risk for congenital abnormalities. Am. J. Obstet. Gynecol. 198, 178.e1-178.e7

Rebordosa, C., Kogevinas, M., Sorensen, H.T., Olsen, J., 2008. Pre-natal exposure to paracetamol and risk of wheezing and asthma in children: A birth cohort study. Int. J. Epidemiol. 37, 583-590.

Rebordosa, C., Kogevinas, M., Bech, B.H., Sorensen, H.T., Olsen, J., 2009. Use of acetaminophen during pregnancy and risk of adverse pregnancy outcomes. Int. J. Epidemiol. 38, 706-714.

Rebordosa, C., Zelop, C.M., Kogevinas, M., Sorensen, H.T., Olsen, J., 2010. Use of acetaminophen during pregnancy and risk of preeclampsia, hypertensive and vascular disorders: A birth cohort study. J. Matern. Fetal Neonatal Med. 23, 371-378.

Robson, S., 2011. Pain relief in pregnancy. O\&G Magazine. 13,1.

Scialli, A.R., Ang, R., Breitmeyer, J., Royal, M.A., 2010. Childhood asthma and use during pregnancy of acetaminophen. A critical review. Reprod. Toxicol. 30, 508-519.

Scialli, A.R., Ang, R., Breitmeyer, J., Royal, M.A., 2010. A review of the literature on the effects of acetaminophen on pregnancy outcome. Reprod. Toxicol. 30, 495-507.

Shaheen, S.O., Newson, R.B., Sherriff, A., Henderson, A.J., Heron, J.E., Burney, P.G., 2002. Paracetamol use in pregnancy and wheezing in early childhood. Thorax. 57, 958-963.

Süzer, Ö., 2008. Farmakoloji Ders Kitab1. 579-580.

WHO, gebelik ve doğumun entegre yönetimi, gebelik ve doğumda komplikasyonların yönetimi, Geneva, 2003, 206, 215-216.

Wilkes, J.M., Clark, L.E., Herrera, J.L., 2005. Acetaminophen overdose in pregnancy. South. Med. J. 98, 1118-1122. 